\title{
Financial Inclusion, Community Capacity Building and Pro-Wildlife Conservation Behavior around the Northern Periphery of Dja Biosphere Reserve, Cameroon
}

\author{
Nashipu Thalut ${ }^{* 1}$, Dobdinga Cletus Fonchamnyo ${ }^{1}$ and Molem Christopher Sama ${ }^{2}$ \\ ${ }^{1}$ Department of Economics, University of Bamenda, Cameroon \\ ${ }^{2}$ Department of Economics, University of Buea, Cameroon
}

(Received April 13, 2020; Accepted May 14, 2020; Published May 27, 2020)

\begin{abstract}
The study examines the contribution of financial inclusion and community capacity building on pro-wildlife conservation behavior among rural households at the Northern Periphery of Dja Biosphere Reserve, the east region of Cameroon. The data were elicited through the survey questionnaire administered on a sample of 279 households involved in the program of conservation in the areas. The study used a cluster sampling approach in grouping proximity villages into four zones and a purposive sampling technique was used in selecting the households. The objective was achieved empirically using three-stage maximum likelihood estimation techniques; factor analysis, confirmatory factor analysis and structural equation modeling. The result shows that financial inclusion and community capacity building had a significant positive effect on pro-wildlife conservation behavior. The magnitude of the effect of financial inclusion on pro-wildlife conservation behavior was even larger than the magnitude of the effect of community capacity building. The findings suggest that financial inclusion and community capacity building had the tendency to reduce the decline in wildlife stocks as it promoted friendly behavior towards wildlife and its habitats. The study, therefore, recommends policies that support financial inclusion and community capacity building that are essential for sustainable conservation since it promotes pro-wildlife conservation behavior.
\end{abstract}

Keywords: conservation, financial inclusion, pro-wildlife, Cameroon

JEL Classification: G20, 015, Q57

\section{INTRODUCTION}

In recent decades, lots of reforms in the area of wildlife conservation have been undertaken by most African countries. These reforms were aimed at curbing the level of species losses due to human activities. Some of the reforms are: (1) the convention of biological diversity, (2) convention on international trade in endangered species of fauna and flora, (3) the UN Food and agricultural organization on sustainable management of natural resources and ecosystem, (4) the global environmental facility (GEF), and (5) the intergovernmental science-policy platform on

* Corresponding author email: nashiputhalut@yahoo.com ISSN 2615-6075 online; ISSN 2615-6946 print @UWG Press, 2020

OJS http://publishing-widyagama.ac.id/ejournalv2/index.php/jsed/ biodiversity and ecosystem services at the international level to mention a few. Despite these laudable efforts in the area of wildlife conservation in Africa and the world at large and Cameroon in particular, the decline in wildlife stocks still remains a major challenge (Ariya \& Momanyi, 2015; Bouché et al., 2011; Ogutu et al., 2016; Scholte, 2011).

According to the global wildlife program in 2015, every day over 50 elephants, 3 rhinos, and approximately 100 thousand pangolins were slaughtered for their ivories, horns, and scales. In 2016, world wildlife crime reports indicated that pangolin was killed for its meat and scales every 5 minutes, every 26 minutes an elephant was killed in the world (UNODC, 2016). African rhinos were estimated to be poached every 8 hours. The reports further explained that in the 1960s, the 
African population of rhinos was estimated at 100 thousand while in 2016, the rhino's population was estimated at five thousand. Another report according to the Great Elephant Census, between 2007 and 2014, revealed that the population of African elephants declined (Chase, Schlossberg, Sutcliffe, \& Seonyatseng, 2018).

International union of conservation of nature (IUCN) reports in 2016 attributes the loss to surge in poaching and habitat loss (Thouless et al., 2016). Some studies argued that the continuous decline in wildlife population in Africa is attributed to human actions (Ariya \& Momanyi, 2015; Bouché et al., 2011; Ogutu et al., 2016; Scholte, 2011). The losses do not only destroy the ecosystems but also destroy wildlife tourism.

The traditional and protectionist approach of wildlife conservation which involved the establishment of protected areas, restriction of access and the use of natural resources in the protected areas have failed to further value the forest species and ecosystems as well as to improve on the lives of those who live around the protected areas. As it is argued that the local community initially depended on the natural resources in the protected areas where the reserve was created (Ariya \& Momanyi, 2015; Epanda et al., 2019). Due to lack of support to the local people who reside around the protected areas, they have developed a retaliatory behavior in the forms of killing wildlife, poaching, and destruction of natural habitat (Seidensticker, 2010).

Based on this justification new global environmental facility (GEF) and World Bank funding, it is suggested that an incentive base is the best alternative approach in conservation practices as it can ensure proper management of protected areas. While according to Muhumuza \& Balkwill (2013), the failure of the protectionist approach to further value the wildlife is because it failed to take into account the socio-economic and human dimension of biodiversity conservation. Restriction of the local people from accessing resources from the protected areas without any adequate compensation in terms of capacity building towards an alternative source of income has implications on both the livelihoods of the local community and the wildlife community. One of the implications, for instance, is that the local community cannot actively participate in the implementation of the wildlife reforms due to lack of capacity building. In addition, most of the financial resources to implement the wildlife conservation reforms are from the government, though international donors also contribute much to support the wildlife conservation activities. However, these funds are hardly enough to support the wildlife conservation efforts.

Walpole \& Wilder (2008) emphasized on building human capital, natural, physical, financial, and institutional capacity as well as empowerment, security, and network development as an important tool towards achieving sustainable conservation. It is equally argued that financial support for wildlife conservation projects is very important although it is often not sufficient to meet up the targeted budget. In addition, financial support for projects is one of the important steps towards improving the livelihood outcome of households in protected areas. The importance of financial inclusion in reducing inequality of opportunities among households cannot be over emphasized. Financial inclusion is widely accepted as not only a progrowth but also a pro-poor as it plays an important role in reducing poverty globally (Demirgüç-Kunt, Honohan \& Beck, 2008).

The theory of reasons and actions (TRA) developed by Ajzen and Fishbein in 1975 assumed that humans are rational and that they respond to incentives (Ajzen \& Fishbein, 1975). The TRA suggests that behavior outcomes can be predicted by examining individual attitudes about behavior and intent to perform the behavior (Fang, $\mathrm{Ng}$, Wang, \& Hsu, 2017). Attitudes are derived from individuals' beliefs about behavior as well as the appraisal of the advantages and disadvantages of performing the behavior. This theory suggests attitudes and behavioral intention towards wildlife conservation as possible mediators, although the testing of mediation is not the primary focus of the paper.

The study aims at examining the influence of financial inclusion and community capacity building on pro-wildlife conservation behavior among rural households at the Northern Periphery of Dja Biosphere Reserve, the east region of Cameroon. 


\section{RESEARCH METHOD}

The study adopted both qualitative and quantitative research designs. As in the qualitative approach, questionnaires were used as the main tool for collecting the primary data. The study explores the extent to which financial inclusion and capacity building influence pro-wildlife conservation behavior among households at the Northern Periphery of Dja in the East Region of Cameroon. The study followed the ideology noted in the literature of Fang et al. (2017); Gandiwa, Heitkönig, Lokhorst, Prins, \& Leeuwis (2013); Tagg et al., (2018) who argue that increasing environmental problems have imposed a substantial threat to environmental sustainability, and there is an urgent call for response in terms of efforts to enhance environmental friendly behavior.

\section{Method of Sampling}

The study used both cluster and purposive sampling approaches. This was because the members of the population were difficult to be reached, given that they were mostly farmers and hunters. An advantage of using purposive sampling is that it is easy and convenient to administer since it relies upon the judgment of the experts to draw the sample (Epanda et al., 2019).

Table 1. Number of Households Surveyed

\begin{tabular}{lccr}
\hline Villages & $\begin{array}{c}\text { Estimated } \\
\text { number of } \\
\text { inhabitants }\end{array}$ & $\begin{array}{c}\text { Estimated } \\
\text { Number } \\
\text { Households }\end{array}$ & $\begin{array}{c}\text { Number of } \\
\text { Households } \\
\text { surveyed in each } \\
\text { village (\%) }\end{array}$ \\
\hline Bintsina & 145 & 27 & $9(3.23)$ \\
Bitsil & 346 & 63 & $16(5.73)$ \\
Djolempoum & 193 & 35 & $17(6.09)$ \\
Doumo Mama & 429 & 78 & $20(7.17)$ \\
Doumo Pierre & 90 & 16 & $6(2.15)$ \\
Echou & 413 & 75 & $9(3.23)$ \\
Ekok & 179 & 56 & $35(12.54)$ \\
Kabolone II & 49 & 42 & $20(7.17)$ \\
Kompia & 800 & 145 & $10(3.58)$ \\
Madjuih II & 155 & 28 & $9(3.23)$ \\
Malen II & 90 & 60 & $24(8.60)$ \\
Malen V & 129 & 24 & $16(5.73)$ \\
Mboumo & 1249 & 227 & $7(2.51)$ \\
Medjoh & 126 & 23 & $13(4.66)$ \\
Nemeyomg & 323 & 59 & $12(4.30)$ \\
Ngoulminanga & 131 & 43 & $28(10.04)$ \\
Ntoumzouk & 82 & 24 & $16(5.73)$ \\
Pallisco & 142 & 26 & $12(4.30)$ \\
Total & 5071 & 1051 & $279(30.26)$ \\
\hline Source: Adapted from
\end{tabular}

Source: Adapted from (Epanda et al., 2019).

The inhabitants of 18 villages were divided into four zones using a cluster sampling approach. Purposive sampling was used in selecting the households. The villages in zone 1 were: Malen $\mathrm{V}$ and Doumo Pierre, the villages in zone 2 include Ntibonkeuh, Kabolone II, Nemeyomg, Bintsina, Medjoh, Ngoulminanga, Kompia, while the villages in zone 3 include; Madjuih II, Echou, Malen II, Bitsil, and Doumo Mama. In zone 4, Mboumo, Ekok, Djolempoum, and Pallisco Eboumrtoum were part of the sample. The total sample size for the study was 279 as observed in Table 1 . The sample size was found to be appropriate following the recommendation of Schreiber et al., (2006) and Hoe (2008). Schreiber et al.,(2006) suggest that a minimum sample size of 100 for multivariate study using maximum likelihood is good. Hoe (2008) also argues that a minimum sample of 200 is good for any statistical analysis.

\section{Model Specification}

Gifford \& Nilsson (2014) posit that having relevant knowledge and information about environmental issues have little effects in decision making but rather the understanding of the behavior that individuals hold is of utmost importance. The behaviors of individuals can be better understood through their attitudes, beliefs, and intentions (Ajzen \& Fishbein, 1975). The causal relationships between financial inclusion, community capacity building, and pro-wildlife conservation behavior are specified using the direct and indirect effect model. The direct effect functional form is defined by:

$$
\text { PWCB }=f(F I, C A P B)
$$

Where;

PWCB is pro-wildlife conservation behavior while FI is financial inclusion, and CAPB is community capacity building. The indirect functional form is given by;

$$
P W C B=f(F I(C A P B))
$$

Equation 1 shows the direct functional relationship between community capacity building, financial inclusion and pro-wildlife conservation behavior meanwhile equation 2 shows the effect of financial inclusion on pro-wildlife conservation behavior mediated by community capacity building. In other words, equation 2 shows that financial inclusion does not only has a direct effect on prowildlife conservation behavior, it also has an indirect effect through capacity building as well as 
through attitudes and behavior intentions. From the direct and indirect functional forms, we used the pictorial and empirical model as seen in Figure 1, equation 3 and 4.

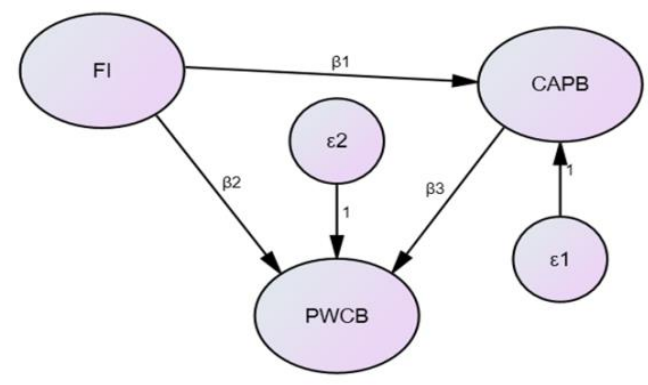

Figure 1. Hypothesized conceptual latent structure model of pro-wildlife conservation

The pictorial hypothesized specified model in Figure 1 is the shortened form of the pro-wildlife conservation since the mediators, variable attitudes and behavioral intentions are not included. The non-inclusion of attitudes and behavioral intention towards conservation is to avoid the cumbersomeness of presenting the framework at this level and when presenting the results. Figure 1 shows that the effect of financial inclusion (FI) on community capacity building is captured by the coefficient $\beta 1$. The effect of community capacity building on pro-wildlife conservation is captured by the coefficient $\beta 2$. The direct effect of financial inclusion on pro-wildlife conservation is captured by the coefficient $\beta 3$. The parameters $\beta 1, \beta 2$, and $\beta 3$ measure the extent to which one construct is related to another construct in the study. The parameters were estimated using maximum likelihood estimation technique of structural equation modelling. These parameters are technically called regression weight. The parameter $\varepsilon 1$ measures the errors of financial inclusion in the prediction of community capacity building while $\varepsilon 2$ is the error measurement in the prediction of prowildlife conservation behavior by the two constructs; financial inclusion and community capacity building. The pictorial diagram in Figure 1 shows the direct and indirect effects of financial inclusion on pro-wildlife conservation behavior. There are two types of measurement models in the structural equation model; inner and outer models. The outer measurement model shows the relationship between the constructs and the indicators. It is otherwise called the factor structure. The inner model shows the relationship between one construct in the prediction of another construct and prediction error measurement as seen in Figure 1. It is also called the latent structure model.

Direct specification of the econometric model is

$$
\mathrm{PWCB}_{i}=\beta_{1} \mathrm{FI}_{\mathrm{i}}+\beta_{3} \mathrm{CAPB}_{\mathrm{i}}+\varepsilon 2
$$

In this case, $\beta 2$ and $\beta 3$ are the parameters that measure the extent to which financial inclusion and capacity building relate to pro-wildlife conservation behavior. The subscript i represent that the observations were collected over individuals. The models are specified without intercept because the standardized value of a constant is zero. The theoretical expectations of the sign of the coefficients are; $\beta 2>0$ and $\beta 3>0$.

Indirect specification of the econometric model is

$$
\mathrm{PWCB}_{\mathrm{i}}=\beta_{2} \mathrm{FI}_{\mathrm{i}} \cdot\left(\beta_{3} \mathrm{CAPB}_{\mathrm{i}}+\varepsilon 1\right)+\varepsilon 2
$$

Furthermore, mathematical exposition of factor analysis is presented in the Appendix.

\section{Statistical and Validation Analysis}

The data were quantified, coded, and keyed in the software Statistical Package of Social Science (SPSS) version 23 and Amos version 21 to obtain the quantitative data and to present the model specification.

Discriminant validity (DV) captures the extent to which a construct is distinct from other constructs (Carmines, \& Zeller, 1979). One of the common measures of discriminant validity is cross-loadings. The discriminant validity in the study was established comparing the square of the average variance extracted with the coefficient of correlation between the constructs. Based on Fornell \& Larcker (1981) criteria, if the square of the average variance extracted is greater than the coefficient of correlation between financial inclusion and community capacity building for instance; the decision rule is that there is evidence of discriminant validity.

Convergent validity is the degree of agreement between two or more indicators of the same construct (Carmines, \& Zeller, 1979). It measures the extent to which the set of items on the 
questionnaire actually reflects the theoretical latent (or unobserved) construct they are designed to measure. Convergent validity exists if all the loadings factor is greater than 0.5 .

Construct reliability (CR) measures the level of internal consistency of the items under the constructs. The items are considered reliable if the construct reliability is 0.7 and above as recommended by Hulland (1999) and Cronbach (1951). It is, therefore, necessary to check in making sure that all the items in the questionnaire are measuring the same underlying construct and they are not error.

Skewness and Kurtosis were used to test the multivariate normality. Byrne (2013) recommends that a data normally distributed if the skewness for the various items ranges between -2 to +2 while kurtosis score ranges -7 to +7 . Meanwhile, Bentler (1990) suggests a more stringent criterion of 1.96 for both skewness and kurtosis. The outliers test was performed by dividing the Mahalanobis dsquared (MAH-DS) with the number of indicators. According to Bentler (1990), if the sample size is greater than 200 and the value is greater than 4 it means that there is evidence of the potential of an outlier.

\section{RESULT AND DISCUSSION}

\section{Respondent Profile}

The survey sample consisted of 279 respondents, with the majority of males. From Table 2, it is observed that that out of the 279 respondents, $145(52.16 \%)$ were males while 133 $(47.84 \%)$ were females. The result indicates that the distribution of respondents according to gender fairly balanced. The balance of gender in the study is necessary to avoid opinions bias from responses from the two groups.

About $58.99 \%$ of the respondents were monogamy, $14.39 \%$ were single, $18.71 \%$ were polygamy, and $5.40 \%$ were widow while $2.52 \%$ were separated. The finding indicated some level of social cohesion. It is important to note that marital status was considered as indicators of stability and responsibility at the individual and community levels. $7.58 \%$ of the respondents were below 20 years of age, $32.13 \%$ was between 20 to less than 35 years, $27.44 \%$ was between 35 to less than 45 years while $17.69 \%$ and $15.16 \%$ were between 45 to less than 60 years and 60 years plus respectively.

As concerned, most of the respondent $(62.95 \%)$ only attended primary school. $25.9 \%$ of the respondents were in secondary school while $8.27 \%$ did not have any formal education. Out of the total proportion of those samples in the study, less than $1 \%$ of respondents attended university or any other higher institution of learning. The finding on the level of education shows that the level of education of the respondents was very low and it is an indication that those who live around the protected areas may not be able to participate in high skilled jobs, and thus trap in low income earning cycle.

Table 2. Socio-Demographic Profile of Respondents

\begin{tabular}{|c|c|c|}
\hline Variable & Number & Proportion \\
\hline \multicolumn{3}{|c|}{ Gender of households' head } \\
\hline Male & 145 & 52.16 \\
\hline Female & 133 & 47.84 \\
\hline \multicolumn{3}{|l|}{ Age (years) } \\
\hline $18-<20$ & 21 & 7.58 \\
\hline $20-<35$ & 89 & 32.13 \\
\hline $35-<45$ & 76 & 27.44 \\
\hline $45-<60$ & 49 & 17.69 \\
\hline 60 and above & 42 & 15.16 \\
\hline \multicolumn{3}{|l|}{ Education level } \\
\hline No formal education & 23 & 8.27 \\
\hline Primary & 175 & 62.95 \\
\hline Secondary & 72 & 25.90 \\
\hline Tertiary & 8 & 2.88 \\
\hline \multicolumn{3}{|l|}{ Marital status } \\
\hline Single & 40 & 14.39 \\
\hline Monogamy & 164 & 58.99 \\
\hline Polygamy & 52 & 18.71 \\
\hline Widow & 15 & 5.40 \\
\hline Divorced & 7 & 2.52 \\
\hline \multicolumn{3}{|c|}{ Monthly income (in thousand FCFA) } \\
\hline$<30$ & 108 & 38.85 \\
\hline $30-<50$ & 52 & 18.71 \\
\hline $50-<75$ & 23 & 8.27 \\
\hline $75-<100$ & 38 & 13.67 \\
\hline $100-<150$ & 44 & 15.83 \\
\hline $150-<200$ & 1 & 0.36 \\
\hline 200 and above & 12 & 4.32 \\
\hline \multicolumn{3}{|c|}{ Number of household members } \\
\hline$<5$ & 124 & 45.09 \\
\hline 5 and above & 151 & 54.91 \\
\hline \multicolumn{3}{|l|}{ Access to electricity } \\
\hline Yes & 13 & 4.68 \\
\hline No & 265 & 95.32 \\
\hline
\end{tabular}

When respondents were asked to indicate their monthly income in FCFA, more than one-third 
(38.85\%) of the sample population indicated that they earned less than 30 thousand frs $(<\$ 15$ equivalent) per month. $12(4.32 \%)$ people earned 200 thousand frs $(\$ 100)$ per month and above. The result in Table 2 corroborated to their level of education, as it was indicated that most of the respondent only attended primary school. Considering their level of education as they are mostly into farming, they may not be able to apply high technology to improve their products due to their low level of scholarship. Electricity is an indispensable source of energy for any vibrant economy in the world today. It helps the transformation of both agricultural and industrial products as well as important power support for the service sector.

Lack of electricity can be considered as an important risk factor to poverty. The result in Table 2 indicates that more than $90 \%$ of the sample population agreed that they did not have access to electricity. Those who indicated that they had access to electricity were using solar energy which was not even constant. The lack of access to electricity seemed to suggest that the cost of living around the protected areas was expensive. Lack of electricity also discouraged micro, small mediumsize businesses from locating in those areas, meaning that the local people could not benefit form the expanded set of opportunities that might come with the usage of electricity.

\section{Exploratory Factor Analysis}

At the exploratory level, a measure of sample adequacy was established through the test of Kaiser-Meyer-Olkin and Bartlett's test of sphericity. The result Kaiser-Meyer-Olkin and Bartlett's test of sphericity is as seen in Table 3.

Table 3. KMO and Bartlett's Test

\begin{tabular}{llc}
\hline $\begin{array}{l}\text { Kaiser-Meyer-Olkin Measure of Sampling } \\
\text { Adequacy }\end{array}$ & 0.709 \\
\hline Bartlett's Test & Approx. Chi-Square & 1073.633 \\
of Sphericity & Degree of freedom & 120 \\
& Significance level & 0.000 \\
\hline
\end{tabular}

Table 3 shows the result of KMO and Bartlett's Test of Sphericity. The KMO value of 0.709 is reasonable to conduct a factor analysis. The $\mathrm{p}$ value of Bartlett's test ( $\mathrm{Sig}=0.000$ ), which is below 0.05 , is significant at the $99 \%$ confidence level. This result indicates that the correlations structure is significantly strong enough to perform a factor analysis on the items. The use of factor analysis in the initial stage of data processing is to permit us to; (1) identify the underlying significant manifest indicators of the unobservable variables in the study.

Table 4. Result of Rotated Component

\begin{tabular}{lccccc}
\hline & \multicolumn{4}{c}{ Rotated Component Matrix } \\
\cline { 2 - 5 } & CAPB & FI & PWCB & ATTW & BI \\
\hline B008 & 0.874 & & & & \\
B011 & 0.803 & & & & \\
B019 & 0.794 & & & & \\
E003 & & 0.803 & & & \\
E022 & & 0.736 & & & \\
E006 & & 0.698 & & & \\
E021 & & 0.547 & & & \\
D003 & & & 0.788 & & \\
D004 & & & 0.780 & & \\
D001 & & & 0.648 & & \\
D005 & & & 0.562 & & \\
C008 & & & & 0.844 & \\
C007 & & & & 0.803 & \\
C015 & & & & 0.692 & \\
D014 & & & & & 0.806 \\
D015 & & & & 0.768 \\
\hline
\end{tabular}

Extraction Method: Principal Component Analysis.

Rotation Method: Varimax with Kaiser Normalization.

${ }^{\text {a }}$ Rotation converged in 5 iterations.

Table 4 shows the loading factors pertaining to various constructs. The items which are retained are greater than the cut-off criteria of 0.5 and above. Any other item that did not meet up with the minimum cut-off criteria of 0.5 loading factors (such as items with loading factor of less than 0.5 , 1 , or even negative value) were discarded. The loading factors are the regression weight of each indicator. The loading of an item shows the extent to which an item contributes to the factor. A value close to 1 indicates that an item loads highly on a specific factor. The result in Table 4 shows clearly that the item B008, B011, and B019 load to the factor wildlife capacity building while four items load to factor or construct financial inclusion (E003, E006, E022, and E021). The four items load under the construct pro-wildlife conservation behavior (D001, D003, D004 and D005) while three items load on attitudes (C007, C008 and C015) and two items on behavioral intention (D014 and D015). The measurement of the variables is summarized on Table 4. 
The result in Table 5 shows strong evidence of internal consistency as the reliability of the factor was well above the minimum cut-off criteria of reliability coefficient of 0.5 for variables at the exploratory phase. However, the variable behavioral intention was well below the minimum cut of the criteria, although it was maintained in the study for further investigation at the confirmatory phase of the analyses of the result.

Table 5. Measurability of The Variable and Reliability Result

\begin{tabular}{|c|c|c|c|c|}
\hline Construct & $\begin{array}{c}\text { Item } \\
\text { (Indicator) }\end{array}$ & Description & Dimension & $\begin{array}{l}\text { Chron- } \\
\text { bach's } \\
\text { Alpha }\end{array}$ \\
\hline \multirow[t]{3}{*}{$\begin{array}{l}\text { Capacity } \\
\text { Building }\end{array}$} & B008 & $\begin{array}{l}\text { Capacity building can enhance the skills and } \\
\text { understanding of wildlife policies. }\end{array}$ & Skills and Ability & 0.803 \\
\hline & B011 & $\begin{array}{l}\text { Wildlife conservation is a two-way traffic; it requires } \\
\text { the collaboration of the community and the institutions } \\
\text { such as NGOs, the government, etc. }\end{array}$ & $\begin{array}{l}\text { Community } \\
\text { involvement }\end{array}$ & \\
\hline & B019 & $\begin{array}{l}\text { Knowledge of community needs is an important aspect } \\
\text { of wildlife capacity building. }\end{array}$ & $\begin{array}{l}\text { Psychological need } \\
\text { fulfilment }\end{array}$ & \\
\hline \multirow[t]{4}{*}{$\begin{array}{l}\text { Financial } \\
\text { Inclusion }\end{array}$} & E003 & $\begin{array}{l}\text { Placement of bank branches around the protected } \\
\text { areas encourages savings and access to loans. }\end{array}$ & Financial Penetration & 0.688 \\
\hline & E006 & $\begin{array}{l}\text { Sharing financial information improves knowledge of } \\
\text { the usage of financial services }\end{array}$ & $\begin{array}{l}\text { Knowledge of Financial } \\
\text { services }\end{array}$ & \\
\hline & E021 & The cost associated with financial inclusion is too high. & $\begin{array}{l}\text { Affordability of financial } \\
\text { services }\end{array}$ & \\
\hline & E022 & Access to financial services is affordable. & $\begin{array}{l}\text { Access to financial } \\
\text { Services }\end{array}$ & \\
\hline \multirow[t]{2}{*}{$\begin{array}{l}\text { Attitudes } \\
\text { towards } \\
\text { wildlife }\end{array}$} & C007 & $\begin{array}{l}\text { I think sensitization on wildlife is necessary to change } \\
\text { the perception people have towards wildlife } \\
\text { conservation. }\end{array}$ & Cognitive Attitudes & 0.705 \\
\hline & $\begin{array}{l}\text { C008 } \\
\text { C015 }\end{array}$ & $\begin{array}{l}\text { I love wildlife because they attract tourists. } \\
\text { I like working with conservation agents and tourists. }\end{array}$ & $\begin{array}{l}\text { Affective attitudes } \\
\text { Psychomotor Attitude }\end{array}$ & \\
\hline \multirow[t]{2}{*}{$\begin{array}{l}\text { Behavioral } \\
\text { Intention }\end{array}$} & D014 & I intend to work with wildlife conservation society. & $\begin{array}{l}\text { Support wildlife } \\
\text { conservation }\end{array}$ & 0.445 \\
\hline & D015 & $\begin{array}{l}\text { I am ready to abide by the rules and regulations put in } \\
\text { place by the local community toward wildlife and its } \\
\text { conservation. }\end{array}$ & Respect wildlife laws & \\
\hline \multirow{4}{*}{$\begin{array}{l}\text { Pro-wildlife } \\
\text { conservation } \\
\text { behavior }\end{array}$} & D001 & Wildlife is part of my family. & Empathy & 0.768 \\
\hline & D003 & $\begin{array}{l}\text { I teach my children the importance of wildlife in our } \\
\text { community and society. }\end{array}$ & Wildlife education & \\
\hline & D004 & $\begin{array}{l}\text { It is important to discuss local folk tales that enhance } \\
\text { wildlife conservation to my family and friends. }\end{array}$ & History of wildlife & \\
\hline & D005 & $\begin{array}{l}\text { The local community is ready to promote wildlife } \\
\text { conservation activities in my village. }\end{array}$ & Readiness & \\
\hline
\end{tabular}

Table 6. Result of The Test of Discriminant Validity

\begin{tabular}{lccccc}
\hline & FI & CAPB & ATT & BI & PWCB \\
\hline FI & 0.610 & & & & \\
CAPB & 0.372 & 0.760 & & & \\
ATT & -0.031 & 0.019 & 0.690 & & \\
BI & 0.028 & 0.026 & 0.157 & 0.540 & \\
PWCB & 0.300 & 0.341 & 0.229 & 0.226 & 0.810 \\
\hline
\end{tabular}

The result in Table 6 shows strong evidence of discriminant validity. The finding suggests that the indicators of the construct are unique. In other words, the indicators reflect only the theoretical construct being measure and not the errors or other concepts.
Table 7. Result of The Test of Convergent Validity

\begin{tabular}{cc}
\hline Constructs & $\begin{array}{c}\text { Average Variance Extracted } \\
\text { (AVE) }\end{array}$ \\
\hline CAPB & 0.58 \\
ATT & 0.46 \\
BI & 0.29 \\
PWCB & 0.65 \\
FI & 0.37 \\
\hline
\end{tabular}

The average variance extracted (AVE) was significant as they were above the cut-off criteria of 0.5 recommended by (Fornell \& Larcker, 1981), except for two constructs (financial inclusion and behavioral intention) (Table 7). The results reveal 
that there is evidence of convergence validity between the constructs in the study.

Table 8. Multivariate Normality Test

\begin{tabular}{lrrrr}
\hline Variable & Skew & \multicolumn{1}{c}{ C.R. } & Kurtosis & \multicolumn{1}{c}{ C.R. } \\
\hline D003 & -.521 & -3.550 & -.866 & -2.954 \\
D004 & -.562 & -3.832 & -.874 & -2.980 \\
C007 & -.876 & -5.974 & -.209 & -.713 \\
C008 & -.681 & -4.647 & -.372 & -1.267 \\
C015 & -.560 & -3.816 & -.569 & -1.941 \\
D015 & .309 & 2.106 & -1.385 & -4.721 \\
D014 & -1.503 & -10.250 & 2.206 & 7.522 \\
E022 & -.906 & -6.175 & -.467 & -1.594 \\
E021 & -.893 & -6.086 & -.023 & -.080 \\
E006 & -1.373 & -9.364 & 1.386 & 4.727 \\
E003 & -1.175 & -8.016 & .333 & 1.137 \\
B019 & -.364 & -2.482 & -1.000 & -3.410 \\
B011 & -.716 & -4.883 & -.477 & -1.627 \\
B008 & -.529 & -3.606 & -.866 & -2.953 \\
Multivariate & & & 21.543 & 8.500 \\
\hline
\end{tabular}

The result of the multivariate normality test shows that the variables in the model were normally distributed meanwhile the result of the observations farthest from the centroid
(Mahalanobis distance) shows no evidence of potential outliers (Table 8 ).

\section{Test of Confirmatory Factor Model}

The result of the confirmatory factor analysis (Figure 2) suggests that the factor loadings fulfill the minimum cut-off criteria of 0.5 and above 0.5 . The root mean square of the approximation (RMSEA) is well below the cut off criteria suggested by Byrne (2013) for a good fit. The comparative goodness of fit index (CFA), goodness of fit index (GFI) and adjusted goodness of fit index (AGFI) are both above 0.9 minimum criteria as recommended by Chau (1997) and Segars \& Grover (1998). We were confident the model reproduces that data adequately. In other words, the finding of CFA analyses suggests that the data could reproduce the hypothesized model. This finding satisfied the necessary and sufficient conditions to run a full fledge structural equation model using maximum likelihood estimation technique.

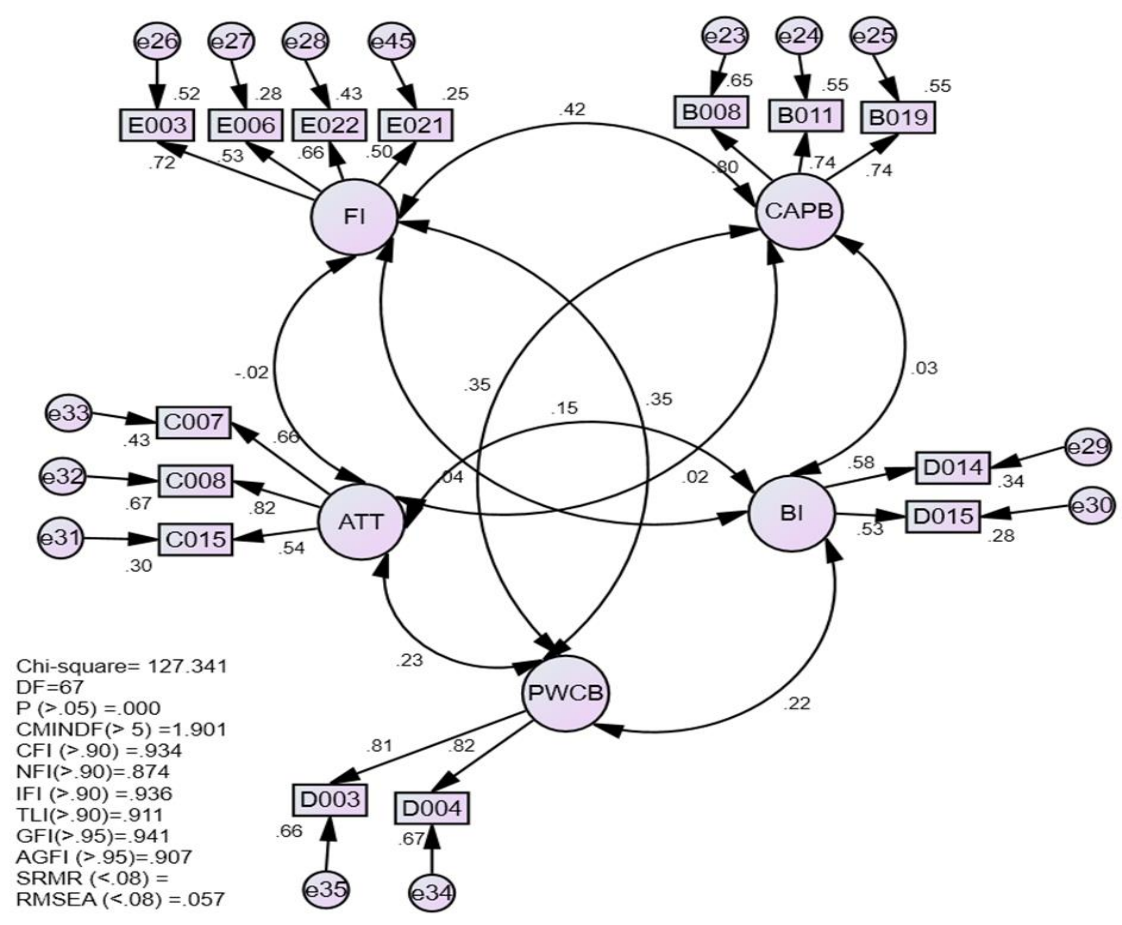

Figure 2. Confirmatory factor model of pro-wildlife conservation behavior 


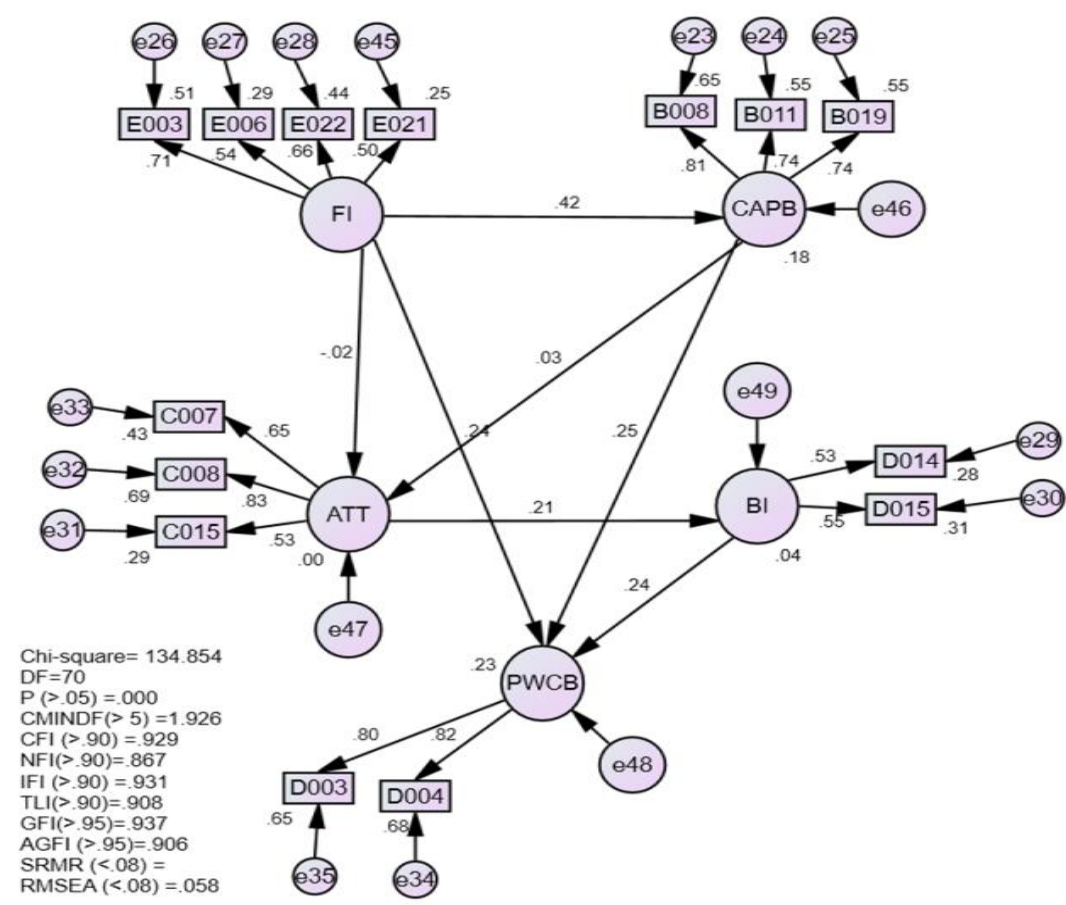

Figure 3. Pro-wildlife conservation model

The result of the unconstraint structural model of pro-wildlife conservation in Figure 3 shows the measurement errors associated with each indicator, standardized regression weight that captured the magnitude of the relationship between the constructs and the manifest indicators. The only pure exogenous latent variable in the study is financial inclusion. The construct wildlife capacity building, attitude towards wildlife and behavioral intention are mediators while pro-wildlife conservation behavior is an endogenous construct.

The results of the findings in Table 9 reveal that financial inclusion had a significant positive direct effect on wildlife capacity building and pro-wildlife conservation behavior. The result equally shows that wildlife capacity building had significant positive direct effects on pro-wildlife conservation behavior. Both financial inclusion and capacity building did not show any significant effects on attitude towards wildlife conservation behavior. The result shows that behavioral intention had a significant positive effect on pro-wildlife conservation behavior.
Table 9. The Result of Path Regression

\begin{tabular}{|c|c|c|c|}
\hline Hypothesized Path & $\begin{array}{c}\text { Estimate } \\
(\mathrm{SE}) \\
{[\mathrm{C} . \mathrm{R}]} \\
\end{array}$ & $\mathrm{p}$-value & Decision \\
\hline FI --> CAPB & $\begin{array}{c}.498^{*} \\
(0.099) \\
{[5.020]}\end{array}$ & 0.000 & Supported \\
\hline CAPB --> PWCB & $\begin{array}{c}.245^{*} \\
(0.082) \\
{[2.988]}\end{array}$ & 0.003 & Supported \\
\hline FI --> PWCB & $\begin{array}{c}.270 * \\
(0.103) \\
{[2.624]}\end{array}$ & 0.009 & Supported \\
\hline BI --> PWCB & $\begin{array}{c}.536 * \\
(0.232) \\
{[2.313]}\end{array}$ & 0.021 & Supported \\
\hline CAPB --> ATT & $\begin{array}{l}.021 \\
(.056) \\
{[.370]}\end{array}$ & 0.711 & $\begin{array}{c}\text { Not } \\
\text { Supported }\end{array}$ \\
\hline FI --> ATT & $\begin{array}{c}-.015 \\
(0.070) \\
{[-0.212]}\end{array}$ & 0.832 & $\begin{array}{c}\text { Not } \\
\text { Supported }\end{array}$ \\
\hline ATT --> BI & $\begin{array}{l}.164 * * \\
(0.083) \\
{[1.975]}\end{array}$ & 0.045 & Supported \\
\hline
\end{tabular}

The result of the findings shows that financial inclusion, capacity building and behavioral intention were direct significant predictors of pro-wildlife 
conservation behavior. The finding reveals that financial inclusion and capacity building did not have a significant effect on attitudes toward wildlife conservation through the attitudes that were found to be significant in predicting behavioral intention to conserve wildlife.

The finding supports the claim of Walpole and Wilder (2008) in the literature of capacity building. They argue that building human capacity is an important tool towards achieving sustainable conservation. In another study by Hoole and Berkes (2010) on recoupling - ecologically systems for biodiversity conservation in Namibia, it shows that the creation of national reserve with the displacement of the local community without adequate support causes conflict between the managers of the reserves and indigenous people.

The findings are also in line With the work of (Kideghesho, Røskaft, \& Kaltenborn, 2007) on factors influencing the conservation behavior of local people living in the Western Serengenti in Tanzania. They found out that people who were evicted when the park was created opposed the activities of wildlife conservation because they were not supported financially. Due to the absence of social networks, they formed retaliatory behavior towards wildlife species.

\section{CONCLUSION AND SUGGESTION}

The empirical findings clearly show that financial inclusion and community capacity building had significant positive effects on pro-wildlife conservation behavior among households at the Northern Periphery of Dja Biosphere Reserve. Even though the effects of financial inclusion in the prediction of pro-wildlife conservation behavior was stronger relative to that of capacity building, both were important in curbing the high dependency of households on wildlife stocks. Besides, behavior intention towards wildlife conservation was proven to be one of the significant factors in predicting pro-wildlife conservation behavior.

The findings suggest that financial inclusion and community capacity building had the tendency to reduce the decline in wildlife stocks as they promoted friendly behavior towards wildlife and its habitats. The study, therefore, recommends that policies that support financial inclusion and community capacity building are essential for sustainable conservation since they promote prowildlife conservation behavior.

\section{ACKNOWLEDGMENTS}

The study acknowledges Tropical Forest and Rural Development (TF-RD) for the excellent assistance in the organization of the fieldwork at Kabolone II. The study also wishes to appreciate the association of Environmental Education, Climate Change, and Poverty Alleviation (EECC-POVA) for the human support assigned to assist in the collection of the data used in the study.

\section{REFERENCES}

Adeyemia, A. A., Pramanikb, A. H., \& Meerac, A. K. M. (2012). A Measurement Model of the Determinants of Financial Exclusion among Muslim Micro-entrepreneurs in Ilorin, Nigeria. Journal of Islamic Finance, 1(1), 30-43. Retrieved from https://journals.iium.edu.my/iiibfjournal/index.php/jif/article/view/3/3

Ajzen, I., \& Fishbein, M. (1975). A Bayesian analysis of attribution processes. Psychological Bulletin, 82(2), 261-277. https://doi.org/10.1037/h0076477

Ariya, G., \& Momanyi, S. (2015). Assessing Wildlife Consumption Awareness and the Attitudes of the Local Lambwe Valley Community towards Ruma National Park, Kenya. Journal of Tourism \& Hospitality, 4(3), 1-6. https://doi.org/10.4172/21670269.1000157

Bentler, P. (1990). Comparative Fit Indices in Structural Models Permalink. Psychological Bulletin, 107(2), 238-246. Retrieved from https://www.ncbi.nlm.nih.gov/pubmed/2320703

Bouché, P., Douglas-Hamilton, I., Wittemyer, G., Nianogo, A. J., Doucet, J. L., Lejeune, P., \& Vermeulen, C. (2011). Will elephants soon disappear from West African Savannahs? PLoS ONE, 6(6). https://doi.org/10.1371/journal.pone.0020619

Byrne, B. M. (2013). Structural Equation Modeling With AMOS: Basic Concepts, Applications, and Programming, Second Edition (2nd ed.). Taylor \& Francis. Retrieved from https://books.google.co.id/books?id=1dHbAAAA $\underline{\text { QBA] }}$

Carmines, E. G., Zeller, R. A., Zeller, R. A., SAGE., \& Sage Publications, inc. (1979). Reliability and 
Validity Assessment. SAGE Publications. Retrieved from https://books.google.co.id/books?id=BN MMD9 BHogC

Chase, M., Schlossberg, S., Sutcliffe, R., \& Seonyatseng, E. (2018). Dry Season Aerial Survey of Elephants and Wildlife in Northern Botswana July - October 2018. Kasane, Botswana. Retrieved from http://elephantswithoutborders.org/site/wpcontent/uploads/2018-Botswana-report-finalversion-compressed-upload.pdf

Chau, P. Y. K. (1997). Reexamining a model for evaluating information center success using a structural equation modeling approach. Decision Sciences, 28(2), 309-334. https://doi.org/10.1111/j.15405915.1997.tb01313.x

Cronbach, L. J. (1951). Coefficient alpha and the internal structure of tests. Psychometrika, 16(3), 297-334. https://doi.org/10.1007/BF02310555

Demirgüç-Kunt, A., Honohan, P., \& Beck, T. (2008). Finance for All?: Policies and Pitfalls in Expanding Access. World bank. Washington, DC. Retrieved from https://openknowledge.worldbank.org/handle/1 $\underline{0986 / 6905}$

Epanda, M. A., Mukam Fotsing, A. J., Bacha, T., Frynta, D., Lens, L., Tchouamo, I. R., \& Jef, D. (2019). Linking local people's perception of wildlife and conservation to livelihood and poaching alleviation: A case study of the Dja biosphere reserve, Cameroon. Acta Oecologica, 97(April), $42-48$. https://doi.org/10.1016/j.actao.2019.04.006

Fang, W. T., Ng, E., Wang, C. M., \& Hsu, M. L. (2017). Normative beliefs, attitudes, and social norms: People reduce waste as an index of social relationships when spending leisure time. Sustainability (Switzerland), 9(10), 1-18. https://doi.org/10.3390/su9101696

Fornell, C., \& Larcker, D. F. (1981). Structural Equation Models With Unobservable Variables And Measurement Error: Algebra and statistics. SAGE Publications Sage CA: Los Angeles, CA. Retrieved from https://books.google.co.id/books?id=OuVVzYBPmAC

Gifford, R., \& Nilsson, A. (2014). Personal and social factors that influence pro-environmental concern and behaviour: A review. International Journal of Psychology, 49(3), 141-157. https://doi.org/10.1002/ijop.12034

Gorsuch, R. L. (1990). Common Factor Analysis versus Component Analysis: Some Well and Little Known Facts. Multivariate Behavioral Research, 25(1), 33-39. https://doi.org/10.1207/s15327906mbr2501 3

Hoe, S. L. (2008). Issues and procedures in adopting structural equation modelling technique. Journal of Applied Quantitative Methodes, 3(1), 76-83. Retrieved from https://pdfs.semanticscholar.org/f9aa/69d52749 347ea47a23f827dc50795969110f.pdf

Hoole, A., \& Berkes, F. (2010). Breaking down fences: Recoupling social-ecological systems for biodiversity conservation in Namibia. Geoforum, 41(2), 304-317. https://doi.org/10.1016/j.geoforum.2009.10.00 $\underline{9}$

Hulland, J. (1999). Use of Partial Least Squares (PLS) in Strategic Management Research: A Review of Four Recent Studies. Strategic Management Journal, 20(4), 195-204. https://doi.org/10.1038/aps.2012.31

Jolliffe, I. (1989). Latent Variable Models and Factor Analysis. Applied Statistics, 38(3), 521. https://doi.org/10.2307/2347739

Kideghesho, J. R., Røskaft, E., \& Kaltenborn, B. P. (2007). Factors influencing conservation attitudes of local people in Western Serengeti, Tanzania. Biodiversity and Conservation, 16(7), 2213-2230. https://doi.org/10.1007/s10531006-9132-8.

Muhumuza, M., \& Balkwill, K. (2013). Factors Affecting the Success of Conserving Biodiversity in National Parks: A Review of Case Studies from Africa. International Journal of Biodiversity, 2013, 1-20. https://doi.org/10.1155/2013/798101

Ofeh, M. A., \& Thalut, N. (2018). Financial Exclusion and Sustainable Rice Production: A Model of Poverty Reduction in Ndop, Cameroon. SSRG International Journal of Economics Management Studies ( SSRG-IJEMS ), 5(12), 815. https://doi.org/10.14445/23939125/ijemsv5i12p102

Ogutu, J. O., Piepho, H. P., Said, M. Y., Ojwang, G. O., Njino, L. W., Kifugo, S. C., \& Wargute, P. W. (2016). Extreme wildlife declines and concurrent increase in livestock numbers in Kenya: What are the causes? PLOS ONE, 11(9), $1-46$. https://doi.org/10.1371/journal.pone.0163249 
Scholte, P. (2011). Towards understanding large mammal population declines in Africa's protected areas: A West-Central African perspective. Tropical Conservation Science, 4(1), 4-11. https://doi.org/10.1177/194008291100400102

Schreiber, J. B., Stage, F. K., King, J., Nora, A., \& Barlow, E. A. (2006). Reporting structural equation modeling and confirmatory factor analysis results: A review. Journal of Educational Research, 99(6), 323-338. https://doi.org/10.3200/JOER.99.6.323-338

Segars, A. H., \& Grover, V. (1998). Strategic information systems planning success: An investigation of the construct and its measurement. MIS Quarterly: Management Information Systems, 22(2), 139-162. https://doi.org/10.2307/249393

Seidensticker, J. (2010). Saving wild tigers: A case study in biodiversity loss and challenges to be met for recovery beyond 2010. Integrative
Zoology, 5(4), 285-299.

https://doi.org/10.1111/j.17494877.2010.00214.x

Thouless, C. R., Dublin, H. T., Blanc, J. J., Skinner, D. P., Daniel, T. E., Taylor, R. D., ... Bouché, P. J. C. (2016). African elephant status report 2016: an update from the African elephant database. Occasional paper series of the IUCN Species Survival Commission, (60), vi + 309pp. https://doi.org/10.2305/IUCN.CH.2007.SSCOP.33.en

UNODC. (2016). World Wildlife Crime Report 2016: Trafficking in Protected Species. New York: United Nations Office on Drugs and Crime. Retrieved from https://books.google.co.id/books?id=ME88DwA $\underline{\text { AQBA] }}$

Walpole, M., \& Wilder, L. (2008). Disentangling the links between conservation and poverty reduction in practice. Oryx, 42(4), 539-547. https://doi.org/10.1017/S0030605308000744 
Appendix. Mathematical exposition of factor analysis used in the study

The study makes use of factor analysis and confirmatory factor analysis. The rational for the use of factor analysis was the factorability of the indicators as well as the dimensional reduction. The purpose of factor analysis is to describe, if possible, the covariance relationships among the observable characteristics of the aforementioned constructs in terms of a few underlings items (Jolliffe, 1989) with unobservable random quantities called factor (Ofeh \& Thalut, 2018). The unobservable variables in the study were: financial inclusion (FI), community capacity building (CAPB), attitude toward wildlife (ATTW), behavioral intentions (BI), and pro-wildlife conservation behavior (PWCB). Factor analysis will permit us to establish whether or not any covariance relationships exist among the observable characteristics of the aforementioned constructs (Ofeh \& Thalut, 2018). The general model specification is expressed as

$$
X_{p .1}=\mu_{p .1}+\Gamma_{m . p} F_{p . m}+\varepsilon
$$

Where the breakdown components of the econometrical exposition of factor analysis in equation 1 are;

$$
\underset{p .1}{X}=\left(\begin{array}{l}
x_{1} \\
x_{2} \\
\cdot \\
x_{p}
\end{array}\right), \underset{p .1}{\mu}\left(\begin{array}{l}
\mu_{1} \\
\mu_{2} \\
\cdot \\
\mu_{p}
\end{array}\right)
$$

$X$ is the outcome or observable variables or indicators. These observed variables are the Likert scale question items on the questionnaire. The study adopted a five-point Likert scale; strongly disagree, disagree, neutral, agree, and strongly agree. $\mu$ is the mean vector of the manifest variable, it has $p$ rows 1 column. The matrix of coefficient $(\underset{p . m}{\Gamma})$ is given as;

$$
\Gamma_{p . m}=\left(\begin{array}{llll}
\lambda_{11} & \lambda_{12} & \cdots & \lambda_{1 m} \\
\lambda_{21} & \lambda_{22} & \cdots & \lambda_{2 m} \\
\cdot & & & \\
\cdot & & & \\
\lambda_{p 1} & \lambda_{p 2} & \cdots & \lambda_{p m}
\end{array}\right)
$$

The coefficient matrix of the factor loading measures the correlation between the factors; financial inclusion, community capacity building, attitude towards the wildlife conservation, behavioral intention, and pro-wildlife conservation behavior and manifest variables. This model assumed that the relationships between the factors and manifest variables are linear (Gorsuch, 1990). The factor matrix denoted $\underset{P X 1}{F}$ is given as;

$$
F=\left(\begin{array}{l}
F_{1} \\
F_{2} \\
\cdot \\
F_{p}
\end{array}\right)
$$

It is assumed that the factor is measured with some degree of errors. These errors are described as idiosyncratic terms which constitute the measurement error, hence the inclusion of the error vector matrix.

$$
\underset{p .1}{\mathcal{E}_{1}}=\left(\begin{array}{l}
\mathcal{E}_{1} \\
\mathcal{E}_{2} \\
\cdot \\
\boldsymbol{\varepsilon}_{p}
\end{array}\right)
$$

Factor analysis assumes that there is no relationship between the factors when explaining the variation in the manifest variables. Thus, they are orthogonal (or independent). Other assumptions of factor analysis are as follows; i) the expected mean of the manifest variables should be equal to the population mean, the covariance of the manifest variables (variability) should be explained by the factor loading and the error. Mathematically, the covariance of the manifest variables is expressed as;

$$
\operatorname{Cov}(X)=\Gamma \Gamma^{T}+\varphi
$$

The Variance-covariance matrix of the manifest variables, which defines expression (6), has two components: the factor loadings with its transpose also called the communality and the unique factor (or the unexplained) which measures the percentages of specific variance of the manifest. Communality measures the percentages of variance explained by the indicator under the underling factors. Ofeh \& Thalut (2018) and Abideen et al., (2012) recommend that the communality should be greater than 0.5. Where $\Gamma \Gamma^{T}$ in expression (6) in the matrix form is given by 


$$
\Gamma \Gamma_{p, m}^{T}=\left(\begin{array}{llll}
\sum_{k=1}^{m} \lambda_{1 k}{ }^{2} & \sum_{k=1}^{m} \lambda_{1 k} \lambda_{2 k} & \cdots & \sum_{k=1}^{m} \lambda_{1 k} \lambda_{p k} \\
& \sum_{k=1}^{m} \lambda_{2 k}{ }^{2} & \ldots & \\
. & & & \\
\sum_{k=1}^{m} \lambda_{1 k} \lambda_{p k} & \cdots & & \sum_{k=1}^{m} \lambda_{p k}{ }^{2}
\end{array}\right)
$$

The diagonal elements of the factor loading matrix in expression (7) measure the variability in the manifest variables. Manifest variables are the indicators used to represent the constructs. The covariance matrix is presented below in the expression (8).

$$
\operatorname{Cov}(\mathrm{X})=\left(\begin{array}{llll}
\sigma_{11} & \sigma_{12} & \cdots & \sigma_{1 p} \\
\sigma_{21} & \sigma_{22} & \cdots & \sigma_{2 p} \\
\cdot & & & \\
\cdot & & & \\
\sigma_{1 p} & 0 & \cdots & \sigma_{p p}
\end{array}\right)
$$

The unique or unexplained variance is given by the vector matrix, which is defined as;

$$
\underset{p . p}{\varphi}=\left(\begin{array}{llll}
\varphi_{11} & 0 & \cdots & 0 \\
0 & \varphi_{22} & \cdots & 0 \\
\cdot & & & \\
\cdot & & & \\
0 & 0 & \ldots & \varphi_{p p}
\end{array}\right)
$$

Considering the matrix in expression 8 and 9 , financial inclusion is assumed to be influenced by observed variables on the questionnaire say $\mathrm{X} 1, \mathrm{X} 2$ and $X p$ as illustrated by the system of structural equations below. The factor structures for financial inclusion are;

$$
\begin{aligned}
& \text { X_1=入_11 FI1+e1 }
\end{aligned}
$$

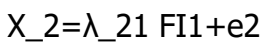

$$
\begin{aligned}
& \text {. }
\end{aligned}
$$

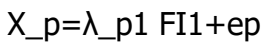

Where $\lambda s$ are factor loadings mentioned supra and e1, e2, ... ep are measurement errors. From the covariance matrix in expression 7, derived a mathematical exposition for the factor financial inclusion.

$$
\sigma_{11}=\lambda_{11}{ }^{2}+\lambda_{21}{ }^{2}+\lambda_{m 1}{ }^{2}+\varphi_{11}
$$

The sum of lambda-square $\left(\lambda_{\mathrm{ik}}{ }^{2}\right)$ is the communality of $\mathrm{Xj}$ in financial inclusion meanwhile $\varphi_{11}$ is the unique variance. It is essential to note that communality represents the percentage variability in observable variables that were extracted using factor analysis. Factor loading is equivalent to the coefficient of determination in the regression analysis; since each is considered as a single regression.

\section{Mathematical exposition of confirmatory factor analysis}

Confirmatory factor analysis shows the relationship between financial inclusion (FI), community capacity building (CAPB), attitude towards wildlife (ATTW), behavioral intentions (BI), and pro-wildlife conservation behavior (PWCB) on one hand and on another relationship between the latent variable and observed variables with its measurement errors.

In the confirmatory factor model in the study, there are five constructs. The constructs have been numbered to permit us to specify the technical structural equations for the various constructs as observed in Figure $1 \mathrm{a}$.

Each construct is measured using a set of question items on the questionnaire. The question items used to capture the constructs were extracted during the exploratory factor analysis. Financial inclusion was measured using $X 1, X 2$ and $\mathrm{X} 3$ as observed in CFA measurement model in figure 1 . Community capacity building was captured using $X 4, X 5$ and $X 6$ while attitudes towards wildlife conservation were measured $X 7, X 8$ and $X 9$. Behavioral intention and pro-wildlife conservation behavior were measured using $\mathrm{X} 10, \mathrm{X} 11, \mathrm{X} 12$, and $\mathrm{X} 13, \mathrm{X} 14, \mathrm{X} 15$ respectively. The observed variables were represented in a rectangle while constructs were represented in a circle while the e1, e2, e3 ..., e15 were the measurement errors.

From the measurement model in Figure $1 \mathrm{a}$, the following factor equations were derived to show the relationships between the concepts and items. The factor structure equations for financial inclusion are;

$$
\begin{aligned}
& X \_1=\lambda \_11 \mathrm{FI} 1+\mathrm{e} 1 \\
& \mathrm{X} \_2=\lambda \_21 \mathrm{FI} 1+\mathrm{e} 2 \\
& X \_3=\lambda \_p 1 \mathrm{FI} 1+\mathrm{e} 3
\end{aligned}
$$




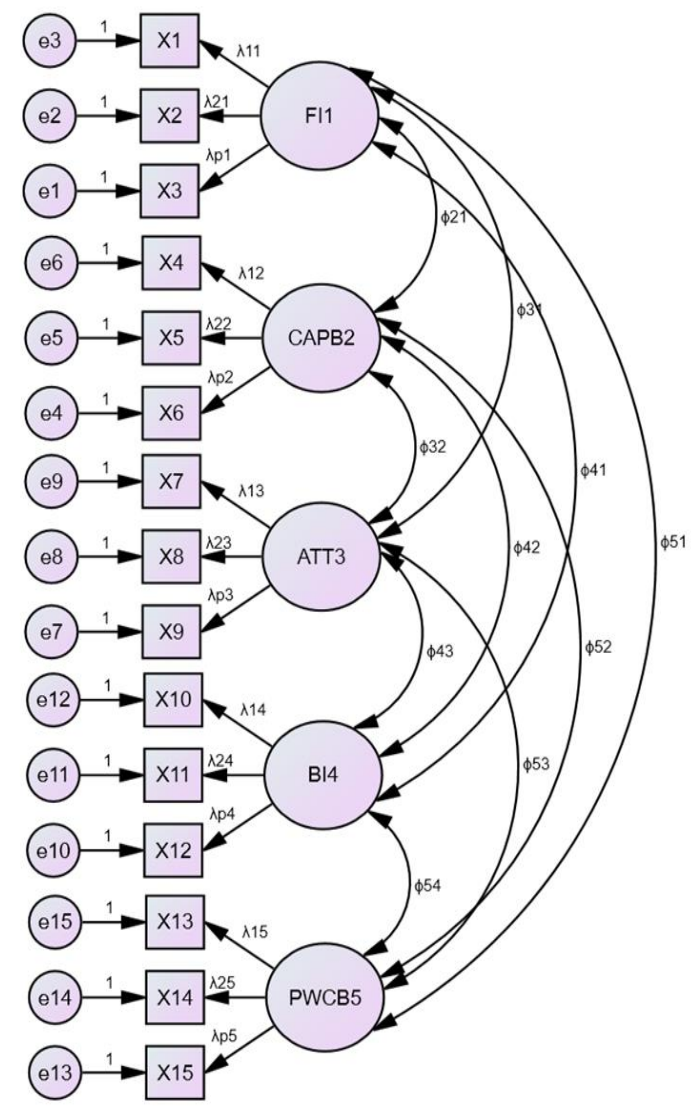

Figure 1a. Confirmatory factor measurement model

The factor structure equations for Community Capacity Building are;

$$
\begin{aligned}
& X \_4=\lambda \_12 \text { CAPB2+e4 } \\
& \text { X_5 }=\lambda \_22 \text { CAPB2+e5 } \\
& X \_6=\lambda \_p 2 \text { CAPB2+e6 }
\end{aligned}
$$

The factor structure equations for attitudes towards wildlife conservation are;

$$
\begin{aligned}
& X \_7=\lambda \_13 \text { АTT3+e7 } \\
& X \_8=\lambda \_23 \text { АТT3+e8 } \\
& X \_9=\lambda \_p 3 \text { АТT3+e9 }
\end{aligned}
$$

The factor structure equations for Behavioral Intention are;

$$
\begin{aligned}
& X \_10=\lambda \_14 \text { BI4+e10 } \\
& X \_11=\lambda \_24 \text { BI4+e11 } \\
& X \_12=\lambda \_p 4 \text { BI4+e12 }
\end{aligned}
$$

The factor structure equations for Pro-Wildlife Conservation Behavior are;
$X \_14=\lambda \_25$ PWCB5+e14

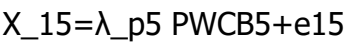

In matrix form,

$$
\left(\begin{array}{l}
X_{1} \\
X_{2} \\
X_{3} \\
X_{4} \\
X_{5} \\
X_{6} \\
X_{7} \\
X_{8} \\
X_{9} \\
X_{10} \\
X_{11} \\
X_{12} \\
X_{13} \\
X_{14} \\
X_{15}
\end{array}\right)=\left(\begin{array}{lllll}
\lambda_{11} & 0 & 0 & 0 & 0 \\
\lambda_{21} & 0 & 0 & 0 & 0 \\
\lambda_{\mathrm{p} 1} & 0 & 0 & 0 & 0 \\
0 & \lambda_{12} & 0 & 0 & 0 \\
0 & \lambda_{22} & 0 & 0 & 0 \\
0 & \lambda_{\mathrm{p} 2} & 0 & 0 & 0 \\
0 & 0 & \lambda_{13} & 0 & 0 \\
0 & 0 & \lambda_{23} & 0 & 0 \\
0 & 0 & \lambda_{p 3} & 0 & 0 \\
0 & 0 & 0 & \lambda_{14} & 0 \\
0 & 0 & 0 & \lambda_{24} & 0 \\
0 & 0 & 0 & \lambda_{p 4} & 0 \\
0 & 0 & 0 & 0 & \lambda_{15} \\
0 & 0 & 0 & 0 & \lambda_{25} \\
0 & 0 & 0 & 0 & \lambda_{p 5}
\end{array}\right)\left(\begin{array}{l}
F I 1 \\
C A P B 2 \\
A T T 3 \\
B I 4 \\
P W C B 5
\end{array}\right)+\left(\begin{array}{l}
e_{1} \\
e_{2} \\
e_{3} \\
e_{4} \\
e_{5} \\
e_{6} \\
e_{7} \\
e_{8} \\
e_{9} \\
e_{10} \\
e_{11} \\
e_{12} \\
e_{13} \\
e_{14} \\
e_{15}
\end{array}\right)
$$

\section{Where;}

Xs: observed variables

$\Gamma: \lambda s$ are factor loadings or regression weights

$\zeta$ : FI1, CAPB2, ATT3, BI4 and PWCB5 are the constructs in the confirmatory model

$$
\varepsilon: \text { e1, e2, e3 ..., e15 are measurement Errors }
$$

The confirmatory factor analysis assumed that the covariance of the mathematical expectation of the latent factor matrix times its transpose is equal to an identity matrix, that is, $\mathrm{E}(\zeta \zeta \mathrm{T})=\psi$. The confirmatory factor model is specified as

$$
X=\Gamma . \zeta+\varepsilon
$$

The covariance- variance of $X$ has two components; explained variance and covariance as well as the correlation between the constructs. The variance of the error measurement is also estimated. With a bit of algebraic expression of equation 18 , we have;

$$
\operatorname{Cov}(\mathrm{X})=\Gamma \psi \Gamma+\Phi
$$

Where $\Gamma \Pi$ in the covariance- variance - matrix in expression 13 of the extracted manifest variables and constructs as observed in expression 12 to 16 is summarized as seen in Figure $2 a$. The outcome of the multiplication of the covariance matrix gives the variance and the covariance of the factor loadings as well as error variances (see Figure 3a).

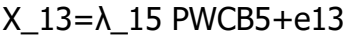




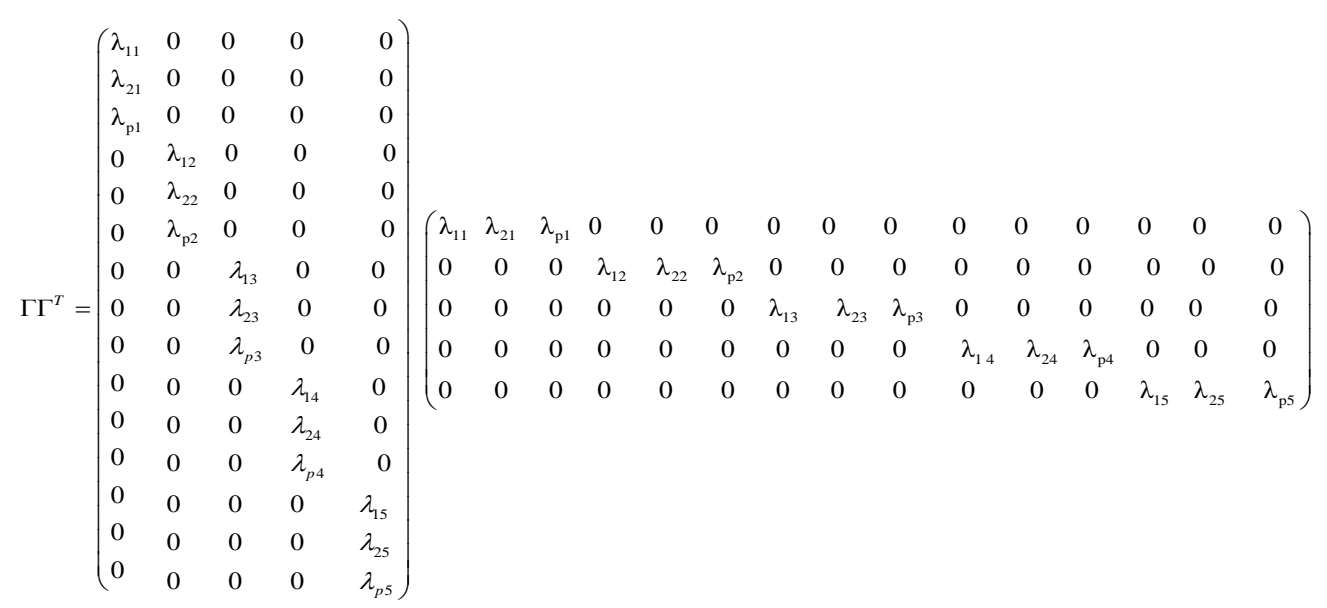

Figure 2a. The extracted manifest variables and constructs

$$
\begin{aligned}
& \Gamma \Gamma^{T}=\left(\begin{array}{llllllllllllllll}
\lambda_{11}^{2} & \lambda_{11} \lambda_{21} & \lambda_{11} \lambda_{\mathrm{p} 1} & 0 & 0 & 0 & 0 & 0 & 0 & 0 & 0 & 0 & 0 & 0 & 0 \\
\lambda_{21} \lambda_{11} & \lambda_{21}^{2} & \lambda_{21} \lambda_{\mathrm{p} 1} & 0 & 0 & 0 & 0 & 0 & 0 & 0 & 0 & 0 & 0 & 0 & 0 & \\
\lambda_{\mathrm{p} 1} \lambda_{11} & \lambda_{\mathrm{p} 1} \lambda_{21} & \lambda_{p 1}^{2} & 0 & 0 & 0 & 0 & 0 & 0 & 0 & 0 & 0 & 0 & 0 & 0 & \\
0 & 0 & 0 & \lambda_{12}^{2} & \lambda_{12} \lambda_{22} & \lambda_{12} \lambda_{\mathrm{p} 2} & 0 & 0 & 0 & 0 & 0 & 0 & 0 & 0 & 0 & \\
0 & 0 & 0 & \lambda_{22} \lambda_{12} & \lambda_{22}^{2} & \lambda_{22} \lambda_{\mathrm{p} 2} & 0 & 0 & 0 & 0 & 0 & 0 & 0 & 0 & 0 & \\
0 & 0 & 0 & \lambda_{\mathrm{p} 2} \lambda_{12} & \lambda_{\mathrm{p} 2} \lambda_{22} & \lambda_{p 2}^{2} & 0 & 0 & 0 & 0 & 0 & 0 & 0 & 0 & 0 & \\
0 & 0 & 0 & 0 & 0 & 0 & \lambda_{13}^{2} & \lambda_{13} \lambda_{23} & \lambda_{13} \lambda_{\mathrm{p} 3} & 0 & 0 & 0 & 0 & 0 & 0 & \\
0 & 0 & 0 & 0 & 0 & 0 & \lambda_{23} \lambda_{13} \lambda_{23}^{2} & \lambda_{23} \lambda_{\mathrm{p} 3} & 0 & 0 & 0 & 0 & 0 & 0 \\
0 & 0 & 0 & 0 & 0 & 0 & \lambda_{\mathrm{p} 3} \lambda_{13} \lambda_{\mathrm{p} 3} \lambda_{23} \lambda_{p 3}^{2} & 0 & 0 & 0 & 0 & 0 & 0 \\
0 & 0 & 0 & 0 & 0 & 0 & 0 & 0 & 0 & \lambda_{14}^{2} & \lambda_{14} \lambda_{24} & \lambda_{14} \lambda_{\mathrm{p} 4} & 0 & 0 & 0 \\
0 & 0 & 0 & 0 & 0 & 0 & 0 & 0 & 0 & \lambda_{24} \lambda_{14} \lambda_{24}^{2} & \lambda_{24} \lambda_{\mathrm{p} 4} & 0 & 0 & 0 \\
0 & 0 & 0 & 0 & 0 & 0 & 0 & 0 & 0 & \lambda_{\mathrm{p} 4} \lambda_{14} \lambda_{\mathrm{p} 4} \lambda_{24} & \lambda_{p 4}^{2} & 0 & 0 & 0 \\
0 & 0 & 0 & 0 & 0 & 0 & 0 & 0 & 0 & 0 & 0 & 0 & \lambda_{15}^{2} & \lambda_{15} \lambda_{25} \lambda_{15} \lambda_{\mathrm{p} 5} \\
0 & 0 & 0 & 0 & 0 & 0 & 0 & 0 & 0 & 0 & 0 & 0 & \lambda_{25} \lambda_{15} & \lambda_{25}^{2} & \lambda_{25} \lambda_{\mathrm{p} 5} \\
0 & 0 & 0 & 0 & 0 & 0 & 0 & 0 & 0 & 0 & 0 & 0 & \lambda_{\mathrm{p} 5} \lambda_{15} & \lambda_{\mathrm{p} 5} \lambda_{25} \lambda_{p 5}^{2}
\end{array}\right) \\
& \varphi=\left(\begin{array}{ccccc}
\phi_{11} & - & - & - & - \\
\phi_{21} & \phi_{22} & - & - & - \\
\phi_{31} & \phi_{32} & \phi_{33} & - & - \\
\phi_{41} & \phi_{42} & \phi_{43} & \phi_{44} & - \\
\phi_{51} & \phi_{52} & \phi_{53} & \phi_{54} & \phi_{55}
\end{array}\right)
\end{aligned}
$$

Figure 3a. Covariance - variance of factor loadings matrix/correlation matrix 